\title{
COVID-19 nas prisões: um desafio impossível para a saúde pública?
}

\author{
COVID-19 in prisons: an impossible challenge for \\ public health?
}

\section{COVID-19 en las cárceles: ¿un desafío imposible para la salud pública?}

\author{
Alexandra Sánchez 1 \\ Luciana Simas 1 \\ Vilma Diuana 1 \\ Bernard Larouze 1
}

doi: 10.1590/0102-311X00083520

As 748 mil pessoas privadas de liberdade (PPL) no Brasil 1, inclusive as 50 mil no Estado de Rio de Janeiro, estão praticamente ausentes dos debates públicos sobre a COVID-19. Entretanto, pode-se conceber condições mais favoráveis à disseminação do SARS-CoV-2, vírus de transmissão aérea e por contato interpessoal, do que nessa população confinada em celas superlotadas, pouco ventiladas e com acesso limitado à água?

Na população livre estima-se que cada infectado contamine 2 a 3 pessoas. Dadas as condições de encarceramento nas prisões brasileiras, pode-se estimar que um caso contamine até 10 pessoas. Assim, em uma cela com 150 PPL, 67\% deles estarão infectados ao final de 14 dias, e a totalidade, em 21 dias. A maioria dos infectados (80\%) permanecerá assintomática ou desenvolverá formas leves, 20\% progredirão para formas mais graves que necessitarão hospitalização, dos quais, $6 \%$ em UTI 2. Nesse contexto, ações de enfrentamento a COVID-19 devem ser antecipadas para que a situação não fique fora do controle. Para predizer a evolução da pandemia nas prisões brasileiras não devemos tomar como referência as prisões europeias, onde a difusão do vírus foi limitada, uma vez que, naquele continente, as celas, quando coletivas, abrigam de modo geral não mais do que quatro presos, em melhores condições de salubridade.

Ressalta-se que a pandemia chega ao Brasil num momento em que o sistema de saúde prisional está frágil e sobrecarregado, o que tem resultado em alta mortalidade por doenças infecciosas potencialmente curáveis, como a tuberculose. Além disto, há PPL idosas e/ou portadoras de doenças associadas à evolução para formas graves e fatais de COVID-19 (grupo de risco), entre as quais, diabetes, cardiopatias, hipertensão, insuficiência renal, asma, HIV/aids e tuberculose. Gestantes e mães com crianças igualmente fazem parte desse grupo por causa de sua vulnerabilidade.

Neste cenário, medidas judiciais de desencarceramento são urgentes e necessárias para reduzir a superlotação que pode alcançar a absurda taxa de 300\% em algumas unidades prisionais. A pandemia exige respostas rápidas, especialmente em países de baixa renda, com condições desumanas e altas taxas de aprisionamento. O desencarceramento é um ponto nodal da resposta à COVID-19 3,4,5. Entretanto, há um intenso debate sob uma falsa dicotomia: de um lado, uma concepção de segurança pública vê grande risco em liberar PPL e, do outro, destacam a percepção do risco de infecção e de morte por COVID-19 imposto às pessoas encarceradas. Alguns resistem, por exemplo, às medidas desencarceradoras contidas na Recomendação no 62/2020 do Conselho Nacional de Justiça 6, que prevê
1 Escola Nacional de Saúde Pública Sergio Arouca, Fundação Oswaldo Cruz, Rio de Janeiro, Brasil.

\section{Correspondência}

A. Sánchez

Escola Nacional de Saúde Pública Sergio Arouca, Fundação Oswaldo Cruz. Av. Brasil 4036, sala 912, Rio de Janeiro, RJ 21040-361, Brasil.

alexandrarsanchez@gmail. com 
a possibilidade de prisão domiciliar ou reavaliação da prisão, como medida protetiva neste período de pandemia, para pessoas acusadas de crimes sem violência ou grave ameaça à pessoa.

Como o Supremo Tribunal Federal tem afirmado reiteradamente, a saúde nas prisões é responsabilidade do Estado 7,8, e as PPL têm direito, no âmbito do Sistema Único de Saúde (SUS), às mesmas condições de prevenção e assistência que o restante da população, conforme dispõe a Constituição Federal, a Lei de Execução Penal, a Política Nacional de Atenção Integral à Saúde de PPL e dispositivos internacionais, tais como as Regras Mínimas das Nações Unidas para o Tratamento de Reclusos 2 . No entanto, a maioria dos documentos sobre o enfrentamento da pandemia de COVID-19 no Brasil não menciona, ou menciona de maneira apenas genérica, a população prisional, enquanto as principais recomendações para a prevenção na população livre, como o distanciamento social e práticas de higiene, como lavagem das mãos, são de muito difícil aplicação nas prisões do país.

As estratégias de prevenção contra a COVID-19 não podem ser limitadas, como em muitos estados, à interdição de visitas, suspensão das transferências entre unidades e interrupção de atividades em grupo, como as esportivas, escolares, educativas e religiosas. É essencial um plano de contingência para as prisões que adeque e torne operacionais as medidas preconizadas para a população geral. Apesar disso, a população prisional não está contemplada nos planos de contingência estadual 9 e municipais do Rio de Janeiro 10,11, que detalham os procedimentos e o papel dos diversos níveis de atenção para prevenção, detecção e confirmação dos casos suspeitos de COVID-19, assistência e vigilância epidemiológica. Essa omissão evidencia a exclusão inicial, de fato, da população prisional das políticas públicas estabelecidas para a população geral, contraria os princípios do SUS e tem reflexos na atenção à saúde, no acesso aos insumos necessários para o enfrentamento da pandemia nas prisões, como testes para diagnóstico e equipamentos de proteção individual (EPI), mas também nas estratégias de vigilância epidemiológica, o que favorece a invisibilidade da situação da COVID-19 intramuros.

Dessa forma, no Rio de Janeiro, é urgente e necessária a inclusão, de fato, das 46 unidades primárias de saúde intramuros, do Sanatório Penal e do Pronto Socorro prisional no sistema de vigilância epidemiológica estadual como unidades notificadoras para que os profissionais de saúde das unidades primárias possam, tempestivamente, notificar eletronicamente os casos de síndrome gripal como casos suspeitos de COVID-19, segundo os critérios definidos para a população livre 9,10,11 e conforme a Resolução Conjunta SES/SEAP 12. Além disso, o sistema prisional, por suas características e potencial de disseminação da COVID-19, deveria ser incluído como unidade sentinela ao lado das dez já existentes, distribuídas nas cinco áreas programáticas do Município do Rio de Janeiro, a fim de acompanhar a evolução e a dinâmica de propagação da pandemia nas diversas unidades prisionais.

No contexto de superlotação das prisões, a estreita vigilância para identificar rapidamente a introdução do vírus nas unidades prisionais e o pronto bloqueio da transmissão são fundamentais para evitar a disseminação massiva. Assim, a quarentena implantada no Rio de Janeiro por 14 dias para todos os ingressos antes de serem alocados nas diversas unidades prisionais é importante para o controle da transmissão, desde que os ingressantes assintomáticos sejam mantidos separados daqueles sintomáticos. Como as prisões brasileiras não têm estrutura que permita o isolamento em cela individual, para o isolamento dos casos suspeitos na população já encarcerada, é preconizado o isolamento de coorte 13 , ou seja, que as PPL com as mesmas características (suspeitos/doentes) sejam isoladas em grupos, em locais diferentes.

A despeito de serem ingressantes ou já encarcerados, é de grande importância que todos que apresentem sintomas compatíveis com COVID-19, mesmo que leves, sejam testados o mais rapidamente possível pelo PCR-RT e, se positivos, fiquem isolados. A priorização da vacinação contra gripe é importante na medida em que, ao reduzir a ocorrência de quadros gripais por outros vírus respiratórios, reduzirá o número de pessoas a serem testadas para COVID-19.

Dessa forma, a testagem das pessoas presas, profissionais de segurança e de saúde com quadro gripal deveria ser considerada estratégia prioritária para o enfrentamento da pandemia nas prisões. Entretanto, até o momento, as PPL não são consideradas como prioritárias para a testagem dos casos suspeitos, e mesmo os que faleceram com suspeita de COVID-19 não foram testados post mortem. Assim, a inexistência de casos suspeitos, confirmados ou de óbitos por COVID-19 nas prisões do Estado do Rio de Janeiro, como informado até o dia 14 de abril de 2020 pela administração penitenciária, pode ser questionada diante da não realização do teste diagnóstico 14 . 
A falta de clareza quanto ao manejo clínico dos casos suspeitos é outro aspecto delicado. Para a população livre, todo paciente com sintomas de resfriado comum ou síndrome gripal deve ser manejado como possível infecção pelo novo coronavírus, de acordo com as orientações do Ministério da Saúde. Os casos classificados como leves devem permanecer em isolamento por 14 dias após o início dos sintomas e os casos graves devem ser encaminhados pelo sistema de regulação de urgências (Vaga Zero) 9,11. Para a população prisional, as práticas atualmente se limitam ao isolamento, sem qualquer definição operacional de fluxo 14 .

Caso não sejam libertadas, as PPL pertencentes ao grupo de risco deveriam ser alocadas em unidade prisional independente, com celas que abriguem pequeno número de presos, com reforço das medidas de prevenção da transmissão e assistência médica regular para reduzir a probabilidade de infecção pelo SARS-CoV-2 e assegurar o tratamento da doença de base. Isso garantiria a assistência adequada diante da sobrecarga do sistema de saúde determinada pela COVID-19 e pelo afastamento dos profissionais de saúde incluídos nesse mesmo grupo de risco.

Na prisão, a percepção do risco à vida e à saúde ocasionada pela COVID-19, somada à restrição à circulação dentro do espaço prisional, à interrupção das atividades laborais, educativas e religiosas são fatores agravantes das tensões, com fortes implicações emocionais para as PPL 15. A suspensão do contato com a família intensifica a sensação de isolamento e insegurança, gerando preocupação com a saúde e a vida dos familiares (Como eles estarão? O que pode estar acontecendo com eles?) e deles mesmos (Será que vou adoecer? Será que teremos assistência ou vamos morrer aqui dentro?). Para reduzir a sensação de perda de controle e ansiedade decorrentes desta situação, é preciso que as PPL sejam informadas sobre as estratégias adotadas pela administração penitenciária para a proteção, prevenção e assistência à saúde e, em especial, que possam manter a comunicação com seus familiares por cartas, telefones e outros meios institucionalmente disponibilizados para este fim. É importante evitar, ainda, a estigmatização e violência que podem ocorrer contra pessoas identificadas como possíveis portadores do vírus.

Nesse cenário, a informação dos profissionais de segurança e de saúde, a disponibilização de EPI, teste diagnóstico, a vacinação contra a gripe e a adequação de suas práticas ao risco de COVID-19 são indispensáveis, além do afastamento do trabalho daqueles que pertencem ao grupo de risco. Em diversos países, a dificuldade de acesso à informação sobre a situação da COVID-19 nas prisões tem sido uma constante. São casos de agentes penitenciários e PPL testados positivos ou com sintomas, divulgados extraoficialmente somente pela mídia, organizações do terceiro setor, familiares ou funcionários dos estabelecimentos prisionais 4 . Acentua-se o papel dos órgãos de fiscalização do Sistema de Justiça (em especial, o Ministério Público e a Defensoria Pública) e da sociedade civil (como o Mecanismo de Prevenção e Combate à Tortura), para conhecer a real situação epidemiológica e assegurar que as medidas preconizadas sejam efetivamente implantadas. Ainda segundo a Organização Mundial da Saúde (OMS), as decisões clínicas devem ser tomadas por profissionais da área da saúde e não devem ser ignoradas ou anuladas por outros funcionários da prisão. O surto de COVID-19 não pode justificar restrições que constituam tortura ou tratamento cruel, desumano ou degradante, nem deve ser usado para impedir inspeções externas por órgãos internacionais ou nacionais independentes 2.

É um equívoco pensar que o bloqueio total das prisões, com isolamento coletivo dos presos e a limitação de informação sobre a situação nas unidades prisionais permitirão evitar a disseminação da COVID-19 no universo carcerário. São necessárias e eticamente indispensáveis a efetiva implantação, com toda a transparência, de estratégias de enfrentamento e vigilância cientificamente fundamentadas e similares às preconizadas para a população geral, para evitar o risco de um drama humanitário que transformaria, mais do que nunca, a prisão no epicentro da necropolítica. 


\section{Colaboradores}

Todos os autores contribuíram com a concepção da ideia central, redação e revisão do manuscrito.

\section{Informações adicionais}

ORCID: Alexandra Sánchez (0000-0001-56171173); Luciana Simas (0000-0003-2494-8747); Vilma Diuana (0000-0002-7373-3446); Bernard Larouze (0000-0001-9906-6293).

\section{Referências}

1. Departamento Penitenciário Nacional, Ministério da Justiça. Levantamento nacional de informações penitenciárias. Atualizado em 09/04/2020. https://app.powerbi.com/vie w?r=eyJrIjoiZTlkZGJjODQtNmJIMi00OTJhL WFlMDktNzRINmFkNTM0MWI3Iiwid CI6ImViMDkwNDIwLTQ0NGMtNDNm Ny05MWYyLTRiOGRhNmJmZThlM (acessado em 14/Abr/2020).

2. WHO Regional Office for Europe. Preparedness, prevention and control of COVID-19 in prisons and other places of detention. Interim guidance; 15 March 2020. http://www.euro. who.int/__data/assets/pdf_file/0019/434026/ Preparedness-prevention-and-control-ofCOVID-19-in-prisons.pdf?ua=1 (acessado em 14/Abr/2020)

3. Amon JJ. COVID-19 and detention: respecting human rights. Health and Human Rights Journal 2020; 23 mar. https://www.hhrjournal. org/2020/03/covid-19-and-detention-respect ing-human-rights/ (acessado em 12/Abr/2020).

4. European Prison Observatory. COVID-19: what is happening in european prisons? http://www.prisonobservatory.org/upload/ 25032020European_prisons_during_covid 19. pdf (acessado em 14/Abr/2020).

5. Assembleia da República. Lei no 9 de 10 de abril de 2020. Regime excecional de flexibilização da execução das penas e das medidas de graça, no âmbito da pandemia da doença COVID-19. Diário da República Eletrónico 2020. https:// dre.pt/home/-/dre/131338919/details/maxi mized.

6. Conselho Nacional de Justiça. Recomendação no 62, de 17 de março de 2020. Recomenda aos Tribunais e magistrados a adoção de medidas preventivas à propagação da infecção pelo novo coronavírus - Covid-19 no âmbito dos sistemas de justiça penal e socioeducativo. https:// www.cnj.jus.br/wp-content/uploads/2020/03/ 62-Recomendação.pdf (acessado em 14/Abr/ 2020).

7. Supremo Tribunal Federal. Tema 365: responsabilidade do Estado por danos morais decorrentes de superlotação carcerária. RE 580252. http://portal.stf.jus.br/processos/detalhe.asp? incidente $=2600961$

8. Supremo Tribunal Federal. Tema 592: em caso de inobservância do seu dever específico de proteção previsto no art. 5o, inciso XLIX, da Constituição Federal, o Estado é responsável pela morte de detento. RE 841526. http:// portal.stf.jus.br/processos/detalhe.asp?inciden te $=4645403$.

9. Secretaria de Estado de Saúde do Rio de Janeiro. Plano de contingência da atenção primária à saúde para o coronavírus no Estado do Rio de Janeiro. https://www.saude.rj.gov.br/aten cao-primaria-a-saude/noticias-saps/2020/03/ atualizacao-plano-de-contingencia-da-aps-pa ra-o-coronavirus-no-estado-do-rio-de-janeiro (acessado em 10/Abr/2020). 
10. Secretaria Municipal de Saúde do Rio de Janeiro. Resolução SMS no 4.330, de 16 de março de 2020. Diário Oficial do Município do Rio de Janeiro 2020; 18 mar.

11. Secretaria Municipal de Saúde do Rio de Janeiro. Resolução SMS no 4.330, de 16 de março de 2020. Anexo I à Resolução SMS no 4.330, de 16 de março de 2020. Nota técnica da Assessoria Especial - Atenção Primária à Saúde. Orientações sobre a prevenção e manejo da transmissão e infecção pelo novo coronavírus (SARS-CoV-2) e organização dos serviços de atenção primária à saúde do Município do Rio de Janeiro (atualizada em 26/03/2020). Diário Oficial do Município do Rio de Janeiro 2020; 27 mar.

12. Secretaria de Estado de Saúde do Rio de Janeiro; Secretaria de Estado de Administração Penitenciária do Rio de Janeiro. Resolução Conjunta SES/SEAP no 736 de 16 de março 2020. Promove recomendações para prevenção e controle de infecções pelo novo coronavírus (COVID-19) a serem adotadas nas unidades prisionais do Estado do Rio de Janeiro. Diário Oficial do Estado do Rio de Janeiro 2020; 17 mar.
13. Ministério da Justiça e Segurança Pública; Ministério da Saúde. Portaria Interministerial no 7, de 18 de março de 2020. Dispõe sobre as medidas de enfrentamento da emergência de saúde pública previstas na Lei no 13.979, de 6 de fevereiro de 2020, no âmbito do Sistema Prisional. Diário Oficial da União 2020; 18 mar.

14. Mecanismo Estadual de Prevenção e Combate à Tortura do Rio de Janeiro. Relatório parcial sobre impactos do COVID-19 no Sistema Prisional do Rio de Janeiro. Informações adicionais até o dia 10 de abril de 2020. https://drive.goo gle.com/file/d/1nz6f9jx3hhp1-_Do8ffI1Kh3h WsTdjc6/view (acessado em 14/Abr/2020).

15. Fundação Oswaldo Cruz. Saúde mental e atenção psicossocial na pandemia COVID-19. Recomendações gerais. https://www.fiocruzbra silia.fiocruz.br/wp-content/uploads/2020/04/ Saúde-Mental-e-Atenção-Psicossocial-na-Pan demia-Covid-19-recomendações-gerais.pdf (acessado em 12/Abr/2020). 